\title{
Proaktif Kişiliğin Kariyer Uyum Yeteneğine Etkisinde Kendini Yetiştirmenin Rolü ${ }^{1}$
}

DOI: $10.26466 /$ opus.583813

*

\section{$\underline{\text { Seyhan Özdemir* }}$}

* Arş. Gör. Dr, Süleyman Demirel Üniversitesi İktisadi ve İdari Bilimler Fak., Isparta/Türkiye E-Posta: seyhanozdemir@sdu.edu.tr

ORCID:0000-0002-3530-6689

\section{Öz}

Bu çalı̧̧manın amacı, kariyer yapılandırma kuramından yola çıkarak proaktif kişiliğin öğrencilerin kariyer uyum yeteneklerine etkisinde kendini yetiştirmenin durumsal aracllı rolünü tespit etmektir. Araştırmanın verileri, 234 öğrenciden oluşmaktadır. Araştırmada anket tekniği kullanılmış olup, hazırlanan anket formu kolayda örnekleme yöntemi kullanılarak araştırmacı tarafindan bizzat öğrencilere ulaştırılmıştır. Anket formunda kullanılan ölçekler ise, Bateman ve Crant (1993) tarafindan geliştirilen Proaktif Kişilik Ölçeği, Porath vd. (2012) tarafindan geliştirilen Kendini Yetiştirme Ölçeği ve Savickas ve Porfeli (2012) tarafindan geliştirilen Kariyer Uyum Yetenekleri Ölçeği kullanılmıştır. Toplanan verilerin analizinde, IBM SPSS 25 ve AMOS 24 programları kullanılarak betimleyici istatistikler, doğrulayıcı faktör analizi, korelasyon ve bootstrap regresyon analizleri kullanılmıştır. Yapılan analizler neticesinde, prokaktif kişilik, kariyer uyum yeteneği ve kendini yetiştirme boyutları arasında pozitif yönlü anlamlı bir ilişki olduğu tespit edilmiştir. Ayrıca proaktif kişiliğin kariyer uyum yeteneği üzerine etkisi pozitif yönlü ve anlamlıdır. Son olarak ise, proaktif kişiliğin, kariyer uyum yeteneği üzerine etkisinde kendini yetiştirmenin aracı rolü tespit edilmiştir.

Anahtar Kelimeler: Proaktif kişilik, Kariyer uyum yeteneği, Kendini yetiştirme, Üniversite öğrencileri, Aracilik

\footnotetext{
${ }^{1}$ Bu çalışma, 02-04 Mayıs 2019 tarihleri arasında düzenlenen 18. Uluslararasi İşletmecilik Kongresinde sunulan bildirinin genişletilmiş halidir.
} 


\title{
The Role of Self Thriving in the Effect of Proactive Personality on Career Adaptability
}

\begin{abstract}
The aim of this study is to determine the mediating role of self-thriving in the effect of proactive personality on career adaptation skills based on career structuring theory. The data of the study consisted of 234 students. The survey technique was used in the research, and the questionnaire was delivered to the students by the researcher by using convenience sampling method. The scales used in the questionnaire were: Proactive Personality Scale developed by Bateman and Crant (1993), Self-Training Scale developed by Porath et al. (2012) and Career Adaptation Capabilities Scale developed by Savickas and Porfeli (2012) was used. Descriptive statistics using IBM SPSS 25 and AMOS 24 programs, confirmatory factor analysis, correlation and bootstrap regression analyzes were used to analyze the collected data. As a result of the analyzes, it has been found that there is a positive positive relationship between proactive personality, career adaptability and self-thriving dimensions. Furthermore, proactive personality has a significant positive effect on career adaptability. Finally, it has been determined that self-thriving plays a mediating role in the effect of proactive personality on career adaptation skills.
\end{abstract}

Keywords: Proactive personality, Career adaptability, Self- thriving, University students, Mediating 


\section{Giriş}

Sürekli ve çok hızlı bir şekilde çevresel faktörlerin değiştiği, bireysel rekabetin giderek arttı̆̆1 günümüzde, artık bireyler sadece mevcut eğitim programlarının gelecekteki kariyer beklentilerini karşılamada yeterli olamayacağının bilincine varmıştır. Öğrenciler açısından bakıldığında ise, günümüz rekabet ortamında sürekli gerçekleşen değişime ayak uydurabilmek için değişime ve öğrenmeye açı, kendini yetiştirebilen kişiler önem arz etmektedir. Bunun için proaktif özelliğe sahip olmak, motive olma, öğrenmeye istekli olma, muaffak olma ve çıktısında da iyi kariyer basamağına sahip olmayı hedeflemektedir (Parker vd., 2010).

Özellikle yurtdışı literatüründe karşımıza çıkan ve örgütsel davranış değişkeniyle ilişkisi ortaya konulan değişkenlerden birisi de "Thriving" kavramıdır. Bu kavram ile ilgili Türkçe literatüründe sınırlı sayıda çalışma bulunmaktadır. Özellikle Koçak (2017) yapmış olduğu çalışmasıyla "Thriving" kavramını "gelişen ve yetişen" şeklinde Türkçe yazına katkıda bulunmuştur. Buradan hareketle içinde öğrenme ve canlılık barındıran kavramın kişilik ve kariyer ile ilişkisi ele alınmıştır.

$\mathrm{Bu}$ çalışma, proaktif kişilik ve kariyer uyum yeteneği arasındaki ilişkinin temelini oluşturan mekanizmayı araştırmak için aracılık modelini inceleyerek bu alana katkı sağlamaktır. Bireylerin hem canlılık hem de öğrenme hissi yaşadığı psikolojik durum ile ilgili olan gelişmenin, proaktif kişiliğin etkisini kariyer uyum sürecinin oluşum sürecine aktaran bir aracı olarak hizmet ettiğini öne sürülmektedir. Bu yüzden kendini yetiştirmenin rolü belirlenmeye çalışılmıştır. Yurtdışında yapılan çalışmalarda kendini yetiştirme ile ilgili model çalışılmış, ancak Türkçe yazında çalışmalara rastlanılmamıştır. Bu anlamda çalışmanın literatüre katkı olacağı düşünülmektedir.

\section{Kavramsal Çerçeve}

Bu başlık altında çalışmada ele alınan Kariyer Uyum Yeteneği, Proaktif Kişilik ve Kendini Yetiştirme kavramları açıklanıp, aralarındaki ilişkiler açıklanmaya çalışılacaktır. 


\section{Kariyer Uyum Yeteneği}

Kariyer uyum yeteneğini, kariyer yapılandırma kuramına oturan merkezi bir kavramdır. Kariyer yapılandırma kuramı, bireylerin kişisel ve sosyal yapılandırmacılık yoluyla kariyerlerini nasıl inşa ettiklerine açılama getirmektedir (Savickas, 2005). Kariyer uyum yeteneği, kişilerin kariyer gelişimine dair görevlerin, iş ya da okul değiştirme gibi geçişlerin ya da iş kaybı gibi travmatik durumların üstesinden gelmede sahip oldukları başa çıkma becerileri olarak tanımlanabilir (Savickas ve Porfeli, 2012). Başka bir tanıma göre, "bireylerin iş yaşamları ve kariyerleri ile ilgili karar verme süreçlerinde sahip olmaları gereken kritik becerileri" ifade etmektedir (Duffy, 2010). Bu bakımdan, sosyal ve psikolojik uyum ile kariyer geliştirme arasında kariyer uyum yeteneği bir köprü görevi görmektedir (Skorikov, 2007).

Kariyer uyum yetenekleri kaygı, kontrol, merak ve güven gibi boyutlardan oluşmaktadır; kaygı, kişinin gelecek için becerilerinin farkında olmasi; control, kişilerin gelecekleri ile ilgili kendilerini yönetebilme ve kendileriyle ilgili karar verebilme duygusuna sahip olması; merak, kişilerin etrafını araştırma çabası; güven, kişilerin kariyerle ilgili kendilerine gevenmesidir (Savickas ve Porfeli, 2012).

Kariyer yapılandırma teorisi, mesleki seçim, uyum, meslek seçim sürecinde eşleştirmeler yapmak ve bu eşleştirmeleri anlamlı hale getirmek gibi konuları inceleyen bir yaklaşımdır (Hartung ve Taber, 2008). Kariyer yapılandırma kuramı, bireysel gelişim, psikodinamik motivasyon ve bireysel farklılık konularını bir araya getirerek kariyer konusunda büyük bir meta-teori oluşturmuştur. Böylece mesleki davranışlar konusunda kapsayıcı bir konu ortaya çıkmıştır (Sevinç ve Siyez, 2018). Yine kariyer yapılandırma kuramı kariyer dünyasının kişisel ve sosyal yapılandırma aracılığıyla nasıl oluşturulduğuyla da ilgilenmektedir (Pişkin, 2017).

Kariyer Yapılandırma Kuramı, günümüzün globalleşen dünyada ve sıklaşan iş geçişleri karşısında kişinin kendini merkez konuma getirmeyi başarabilmesi için bireysel yaşamı ile kariyerini uyumlaştırmasının gerekliliğini vurgulamıştır. Gelişimsel ve bireysel farklılıklara dayalı, yaşam boyu öğrenme ve uyum sağlama becerilerini önemseyen bir kariyer danışmanlığı modeli sunmaktadır. Kariyer yapılandırma kuramına göre, ki- 
şilere sadece bir kariyer yolu seçmeleri değil, kendilerini tanımaları, çevreyle olan etkileşimleri ve öğrenmeleri aracılığıyla yaşamlarındaki anlam ve amacı nasıl oluşturduklarının farkına varmaları ve aslında yaşamlarını biçimlendirmelerine yardımcı olmayı amaçlamaktadır (Savickas, 2005). Kuramda bireylerin söz konusu yapılandırmalar aracılığıyla mesleki davranışlarına nasıl anlam yükledikleri ve bu davranışlarını nasıl yönlendirdikleri açıklanmaya çalışılmaktadır (Pişkin, 2017).

\section{Proaktif Kişilik ve Kariyer Uyum Yeteneği}

Proaktif olmak, motive olma, öğrenmeye hevesli, muaffak olma ve sonucunda da kariyer muaffakına sahip olmayı hedeflemektedir. Proaktif bireyler, sadece kendi etrafında değişim gerçekleştirmezler aynı zamanda etraflarında da olumlu değişimler sergileme içerisindedirler. Proaktif davranışlar içsel motivasyonun artmasına neden olmaktadır. Ayrca güçlü içsel motivasyon üreten bir kişilik özelliğinin sonucu proaktif kişlik oluşmaktadır. Bu durumda kurumlardaki işgörenlerin işlerini verimli bir şekilde yapmalarına ve daha çok sorumluluk bilinci oluşmasına katkı sağlamaktadır (Parker vd., 2010).

Proaktif kişiliğe sahip bireyler, dış çevreden daha az etkilenen ve çevresel değişime daha fazla katkı sağlayan kişilerdir. İnsanların çevrelerini etkilemek için harekete geçme eğilimleri kişilere göre farklılık gösterebilmektir. Proaktif bireyler, girişken, fırsatları önceden kollayan, harekete geçer, inisiyatif gösterir ve anlamlı bir değişim ve amaçlarına ulaşana kadar azim ve kararlılıkla çaba gösteren, diğer işgörenlerden ayrışan kişilerdir (Bateman ve Crant, 1993; Gupta ve Bhawe, 2007). Çevreden ve çevresel durumlardan etkilenmeden kendi çevresinde olumlu bir değişiklik gerçekleştiren bireyler proaktif kişilik özelliğine sahip bireyler olarak ifade edilemektedir (Seibert vd., 2001). Proaktif bireyler, iş yaşamlarında ve kariyer basamaklarında daha fazla bağımsız hareket etme ve karar alma yetisine sahiptirler (Siebert vd., 1999).

Proaktif kişilik özelliği gösteren bireyler, herhangi bir sınırlandırmaya kalmadan hedeflerine ulaşana kadar azimle çaba gösteren kişilerdir (Presbitero, 2015). Ayrıca bu kişilik özelliğini gösteren bireyler, işin püf noktalarını iyi öğrenirler, öğrenmeye, harekete geçmeye daha çok isteklidirler ve geri dönütleri izledikleri için daha çok bilgiye ulaşmaktadırlar. Aynı 
şekilde iş yerinde sosyal ilişkileri geliştirmede, etrafındaki insanlarla etkileşim içinde olma ve kuruma uyum sağlama konusunda diğer çalışanlara göre daha başarılıdırlar (Lambert vd., 2006).

Normalde değişim ve eylem odaklı proaktif bireylerin, kariyerle ilgili değişikliklerle aktif olarak ilgilenmeleri, gelişim fırsatlarını keşfetmeleri ve kariyer ihtiyaçları için çalışma ortamları yaratmaları daha muhtemeldir (Bateman ve Crant, 1993). Bu nedenlerden dolayı, proaktif bireyler, kariyer gelişim imkânlarını kolaylaştırmak için aktif olarak adapte edilebilirlik kaynakları geliştirmeye daha eğilimlidir.

Kariyer uyum yeteneğine sahip öğrenciler okul hayatı ile aktör rolünden çıkıp kendi kariyerinin biçimlendiricisi rolüne girmesi; kendine hedefler koymaya başlaması ve özdüzenleme becerileri ile şekillenmeye başlamaktadır (Savickas, 2011). Kariyer uyumu, bireylerin mesleki yaşamlarını dinamik bir şekilde inşa ettikleri ve aynı zamanda içinde bulundukları sosyo-kültürel ve sosyoekonomik koşullar çerçevesinde proaktif olarak değişikliklere uyum sağlama yeteneğini gösteren bir süreci yansıtır (Tladinyane ve Merwe, 2016).

Ayrıca yazın incelendiğinde, kariyer uyum yetenekleri ile ilgili yapılan çalışmalara bakıldığında kişilik değişkeniyle ilgili olduğu görülmektedir. Örneğin, Tolentino ve diğerleri (2014), çalışmalarında Avustralyalı üniversite öğrencilerinde kariyer uyum yetenekleri ölçeğinin psikometrik özelliklerini ve bu ölçeğin kariyer uyum sağlama istekliliği ile proaktif kişilik ilişkisini incelemişlerdir. Cai ve diğerleri (2015), Çinli üniversite öğrencileri üzerinde yürüttükleri çalışmalarında proaktif kişilik ve kariyer uyum yeteneği arasındaki ilişkileri incelemişlerdir. Proaktif kişilik özelliğe sahip kişilerin iş bulmada ve kariyer uyumluluğu sağlamada daha başarılı oldukları bulunmuştur (Brown vd., 2006; Seibert vd., 1999).

\section{Kendini Yetiştirme (Thriving)}

İşte, okulda veya bir kurumda, kendini yetiştirme bireylerin iş hayatında bir kişisel gelişim hissi, işinde daha iyi olma ve ivme kazanmaları olarak görülebilmektedir (Carmeli ve Spreitzer, 2009). Kendini yetiştirmenin iki altı boyutu bulunmaktadır. Öğrenme, kişinin iş yerinde yeni şeyler edinerek işinde daha iyi olmasının altını çizerken; canlılık, enerji dolu, atik ve 
zinde olması halini anlatmaktadır (Porath vd., 2012). İş'te kendini yetiştiren bireylerin tecrübe ettikleri öğrenme de işle ilgili yeni bilgi ve beceriler edinmek, yeteneklerin farkına varmak, kısacası işini daha iyi yapabilmesine katkıda bulunacak her türlü edinimlerdir. Buna kişisel gelişimler ve yeni farkındalıklar da eklenebilir (Koçak, 2017)

Kendini yönetme teorisine göre (self-determination theory) ilişkiler insanların özerklik, yetkinlik ve ilişkide olma ihtiyaçlarını giderebildiği ölçüde insanlara enerji vermektedir (Ryan ve Deci, 2000). Bu ortamların öğrencilere hem öğrenme hem de canlılık hissi yaşayarak okulda kendilerini yetiştirme fırsatı sağlayacağ 1 düşünülmektedir. Proaktif kişilik özelliğine sahip öğrencilerin okul ortamında daha fazla kariyer uyum yeteneklerini geliştirmesi, kendini yetiştiren öğrencilerin ise okul ortamında daha fazla kariyer uyum yeteneği göstermeleri beklenmektedir.

Kuramsal çerçevesini oluşturan diğer bir toeri ise, Maslow'un Kendini Gerçekleştirme Teorisidir. Teori, hiyerarşinin en üst basamağındaki kişinin kendini (olmak istediği kişiliğini) gerçekleştirme ve yaratıcı yeteneklerini kullanma ihtiyaçları yer almaktadır (Tuncer vd., 2011). Bu çalışmada ise okulda kendilerini gerçekleştirme fırsatı sağlayacağı düşünülmektedir

Psikolojik güvenliğin olduğu bir ortamda bireyler orijinal benliklerini ortaya koyarak özerk davranmaktan korkmadıkları, yetkinliklerinin farkına varabildikleri ve ilişki ihtiyaçlarını rahatça karşılayabildikleri için bu ortamların onlara hem öğrenme hem de canlılık hissi yaşayarak işte kendilerini yetiştirme fırsatı sağlayacağı düşünülmektedir (Koçak, 2017).

Öğrencilerin okullarda aldığı kariyer temelli eğitimlerin odak noktasının yeni iş dünyasına uyum sağlama, proaktif düşünme ve toplum için yenilik üretme üzerine kurulması gerektiğini belirtmektedir (Teichler, 1999). İş'te kendini yetiştiren bireylerin tecrübe ettikleri öğrenme de işle ilgili yeni bilgi ve beceriler edinmek, yeteneklerin farkına varmak, kısacası işini daha iyi yapabilmesine katkıda bulunacak her türlü edinimlerdir (Koçak, 2017).

\section{Araştırmanın Yöntemi}

Bu başlık altında araştırmanın modeli, örneklemi ve kullanılan ölçüm araçları hakkında bilgiler verilmiştir. 


\section{Araştırmanın Modeli}

$\mathrm{Bu}$ çalışmada, proaktif kişilik, kariyer uyum yeteneği ve kendini yetiştirme değişkenelerini içeren bir model geliştirilmiştir. Bu hedef doğrultusunda araştırma modeli aşağıda şekilde tasarlanmıştır.

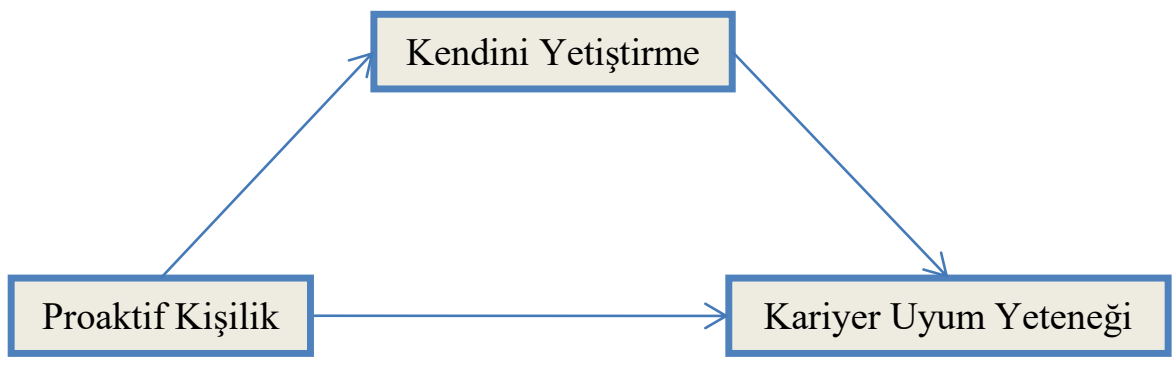

Şekil 1: Araştırma Modeli

Önerilen model doğrultusunda geliştirilen hipotezler aşağıda verilmiştir;

- H1:Proaktif kişiliğin, kariyer uyum yeteneği üzerinde pozitif ve anlamlı etkisi vardır.

- $H_{2}$ :Poraktif kişiliğin, kendini yetiştirme üzerinde pozitif ve anlamlı etkisi vardir.

- $\quad H_{3}:$ Proaktif kişilik, kariyer uyum yeteneğini kendini yetiştirme vasıtasıyla dolayl olarak olumlu yönde etkiler.

\section{Araştırmanın Evreni ve Örneklemi}

Araştırmanın evreni öğrencilerden oluşmaktadır. Örneklem ise Isparta'da Süleyman Demirel Üniversitesi İşletme Bölümü 4. Sınıflardan 234 öğrenci oluşturmaktadır. Bu çalışmada örnekleme yöntemi olarak kolayda örneklem tekniği seçilmiştir. Bu kapsamda, 2018 yılı Kasım ve Aralık aylarında sınıflarda bizzat araştırmacı tarafından ziyaret edilmiş ve çalışmaya katılmayı kabul eden öğrencilere anket formu uygulanmış, 243 öğrenciden veri toplanmış olup 9 adet anket formu tümüne aynı yanıtları verme gibi sebeplerle analiz dışı bırakılmıştır. Sonuç olarak 234 geçerli anket analize tabi tutulmuştur. 
Araştırmaya katılanların \%37,2'si erkek ve \%62,8'i kadındır. Katılımc1ların yaş ortalaması ise 22.55 olarak bulunmuştur. Gelir düzeyleri açısından katılımcılar değerlendirildiğinde $\% 15,8$ düşük, $\% 79,5$ orta ve $\% 4,7$ ise yüksektir. Ailenin yaşadığı yer olarak değerlendirildiğinde $\% 13,2$ köyde, \% 3,0 kasabada, \%34,6 ilçede ve \%49,1 ise ilde yaşamaktadır. Katılımcıların \%56,8 okuduğu bölümü isterken, 43,2 ise istememektedir.

\section{Veri Toplama Araçları}

Bu çalışmada veri toplama amacıyla 3 farklı ölçekten faydalanılmıştır. Bu ölçeklere ilişkin bilgiler aşağıda detaylı şekilde verilmiştir.

Proaktif Kişilik Ölçeği: Bateman ve Crant (1993) tarafından geliştirilen, Akın ve diğerleri (2011) tarafından Türkçe'ye uyarlanmıştır. Ölçek soruları 10 maddeden oluşmaktadır. Tek boyuttan oluşmaktadır. Ölçek 7'li likert ( $1=$ Kesinlikle katılmıyorum ve $7=$ Kesinlikle katılıyorum) şeklindedir. Yapılan (DFA) doğrulayıcı faktör analizi sonucunda ölçeğin geçerliğini belirlenmiştir. Ölçekteki maddelere örnek olarak, "Kendi yaşamımı geliştirmek için sürekli yeni yollar araştırırım" ve "Her zaman bir şeyin en iyisini yapmanın yollarm ararı" "verilebilir.

Kendini Yetiştirme: Porath vd. (2012) tarafından geliştirilen, Koçak (2016) tarafından Türkçe'ye uyarlanan ölçek kullanılmıştır. 2 (canlılık ve öğrenme) boyuttan oluşmaktadır 5'li likert şeklinde tasarlanan ( $1=$ Kesinlikle katılmıyorum, 5= Kesinlikle katılıyorum) şeklindedir. Birinci düzey DFA sonuçları 2 boyutlu yapıyı doğrulamış olup, bu çalışmada tek boyutlu çalışma düşüncesiyle ikinci düzey DFA uygulanmıştır. Ölçeğin ikinci düzey DFA ile elde edilen uyum iyiliği değerleri tek boyutlu yapıyı doğrulamaktadır. Ölçekteki maddelere örnek olarak, "Okuldayken kendimi hayat dolu ve canl hissediyorum." ve "Okuldayken işime yarayacak yeni beceriler ediniyorum." verilebilir.

Kariyer Uyum Yetenekleri Ölçeği: Araştırmada kariyer uyum yeteneklerini ölçmek amacıyla Savickas ve Porfeli'nin (2012) çalışmalarında yer alan ölçekten faydalanılmıştır. Ölçek 24 madde ve 4 alt boyuttan (merak, güven, kontrol ve kaygı) oluşmaktadır. 5'li likert şeklinde tasarlanan (1= 
Kesinlikle Katılmıyorum, 5= Kesinlikle Katılıyorum) ölçekte 2 madde ters puanlanmıştır. Ölçeğin Türkçe'ye uyarlama çalışması Kanten (2012) tarafından gerçekleştirilmiştir. Birinci düzey DFA sonuçları 4 boyutlu yapıyı doğrulamış olup, bu çalışmada tek boyutlu çalışma düşüncesiyle ikinci düzey DFA uygulanmıştır. Ölçeğin ikinci düzey DFA ile elde edilen uyum iyiliği değerleri tek boyutlu yapıyı doğrulamaktadır. Ölçekteki maddelere örnek olarak, "Geleceğimin nasıl olacağını sıklıkla düşünüyorum." ve "Kariyerim ile ilgili seçim yapmak zorunda olduğumun farkındayım." verilebilir.

Çalışmada, yukarıda tanıtımı yapılan 3 ölçekten oluşan anket formu hazırlanmıştır. Araştırmacı bizzat sınıfları dolaşarak gönüllü öğrencilerin ankete katılım sağlamaları istenmiştir.

Araştırma modeli kapsamında oluşturulan hipotezlerin sınanmasına ilişkin çalışmada kullanılan ölçeklerin yapısal geçerlilikleri, DFA yard1miyla araştırılmıştır. DFA sonucunda ulaşılan uyum iyiliği değerleri Tablo 1'de verilmiştir.

Tablo 1. Uyum İyiliği Değerleri

\begin{tabular}{lccccccc}
\hline Model & $\mathbf{x}^{2} / \mathbf{d f}$ & GFI & CFI & AGFI & NFI & NNFI & RMSEA \\
\hline 1.Proaktif Kişilik & 2.35 & .94 & .96 & .90 & .94 & .95 & .07 \\
2.Kendini Yetiştirme & 2.57 & .95 & .99 & .91 & .98 & .98 & .06 \\
$\begin{array}{l}\text { 3.Kariyer Uyum } \\
\text { Yeteneği }\end{array}$ & 1.53 & .95 & .98 & .92 & .95 & .97 & .05 \\
\hline $\begin{array}{l}\text { Kabul edilebilir uyum* } \\
\text { Iyi uyum * }\end{array}$ & $\leq 5$ & $>0.85$ & $>0.90$ & $>0.80$ & $>0.90$ & $>0.90$ & $<0.08$ \\
\hline
\end{tabular}

*(Joreskog ve Sorbom, 1993; Kline, 1998)

Tablo 1 incelendiğinde, ölçeklerle ilgili uyum değerleri kabul edilebilir ve iyi uyum indeksleri değer aralığında olduğu bulunmuştur.

\section{Bulgular}

Araştırmada kullanılan değişkenlerin ortalama değerleri, standart sapmaları, çarpıklık/basıklık değerleri ve pearson korelasyon değerlerine yönelik bulguları Tablo 2'de verilmiştir. Çalışma verileri normal dağılım göstermektedir. Çarpıklık ve basıklık katsayılarının -1 ile +1 aralığında olması verilerin normal dağılım gösterdiği şeklinde ifade edilebilir (Morgan 
vd., 2004). Bu çalışmada da çarpıklık basıklık katsayıları bu değer aralıklarındadir.

Tablo 2. Betimsel İstatistikler ve Değişkenler Arası İlişkiler

\begin{tabular}{|c|c|c|c|c|c|c|c|}
\hline $\begin{array}{l}\text { Değişkenler } \\
(\mathrm{N}=234)\end{array}$ & $\overline{\mathbf{x}}$ & SS & Çarpıklık & Basıklık & 1 & 2 & 3 \\
\hline $\begin{array}{l}\text { Proaktif } \\
\text { Kişilik }\end{array}$ & 5,18 & 0,97 &,- 781 & 1,000 & $(0.83)$ & & \\
\hline $\begin{array}{l}\text { Kendini } \\
\text { Yetiştirme }\end{array}$ & 3,69 & 1,26 &,- 274 &,- 829 & ,229** & $(0.92)$ & \\
\hline $\begin{array}{l}\text { Kariyer Uyum } \\
\text { Yeteneği }\end{array}$ & 4,19 & 0,59 &,- 810 &,- 489 &, $596^{* *}$ & ,334 & (0.90) \\
\hline
\end{tabular}

$\left(p<0,01\right.$ için $\left.{ }^{* *}\right)$. Parantez içerisindekiler boyutların Cronbach Alpha $(\alpha)$ değerlerini göstermektedir.

Tablo 2' de değişkenlere ait aritmetik ortalama değerlerine de yer verilmiştir. Tabloya göre öğrencilerin proaktif kişilik $(5,18 \pm 0,97)$ düzeyleri 7 maksimum puan olarak değerlendirildiğinde yüksek sayılabilecek bir ortalama değere sahiptir. Katılımcların kendini yetiştirme düzeylerinin 5 maksimum puan olarak değerlendirildiğinde orta seviyenin üzerinde bir ortalama değere $(3,69 \pm 1.26)$ sahip olduğu görülmektedir. Son olarak kat1lımcıların kariyer uyum yeteneği düzeylerinin de $(4,19 \pm 0,59), 6$ maksimum puan olarak değerlendirildiğinde yüksek sayılabilecek bir seviyede olduğu tablo 1'de görülmektedir. Tablo 1'de görüldüğü üzere tüm değişkenler arasında pozitif yönlü ve orta kuvvet seviyesinde, $\mathrm{p}<0,01$ düzeyinde anlamlı ilişkiler olduğu tespit edilmiştir.

Aracılık ilişkilerinden oluşan araştırmanın hipotezlerini test etmek amacıyla bootstrap yöntemini esas alan regresyon analizi kullanılmıştır (Hayes, 2018). Hipotezleri test etmek amaciyla yapılan regresyon analizi sonuçları Tablo 3' gösterilmektedir. Aracılık etkisini modern yöntem ile test etmek amacıyla ise IBM SPSS Process Makro uygulaması kullanılmıştır (Hayes ve Matthes, 2009). Modern yaklaşımda modeldeki aracı değişken olan kendini yetiştirmenin, kariyer uyum yeteneği üzerinde dolaylı

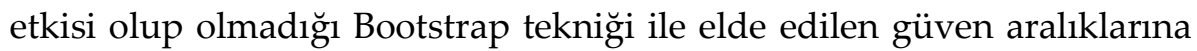
göre tespit edilmiştir (Gürbüz ve Bayık, 2018; Fritz ve MacKinnon, 2007; MacKinnon vd., 2002; Preacher ve Hayes, 2004). 
Tablo 3. Bootstrap Regresyon Analizi Sonuçları $(N=234)$

\begin{tabular}{lcccccc}
\hline \multirow{2}{*}{ Değişkenler } & \multicolumn{3}{c}{ Kendini Yetiştirme } & \multicolumn{3}{c}{ Kariyer Uyum Yeteneği } \\
\cline { 2 - 7 } & $\boldsymbol{B}$ & LLCI & ULCI & $B$ & LLCI & ULCI \\
\hline $\begin{array}{l}\text { Proaktif Kişilik } \\
\text { Kendini Yetiştirme }\end{array}$ & $.297^{* * *}$ & .133 & .460 & .449 & .364 & .533 \\
(Aracı) & - & - & - & $.013^{* * *}$ & .066 & .196 \\
$\boldsymbol{R}^{2}$ & & .052 & & .39 \\
\hline $\begin{array}{l}\text { Bootstrap } \\
\text { dolaylı etki }\end{array}$ & Proaktif Kişilik $\rightarrow$ Kendini Yetiştirme $\rightarrow$ Kariyer Uyum Ye- \\
& \multicolumn{5}{c}{ teneği } \\
\hline
\end{tabular}

$p<.001 . L L C I=$ Lower level confidence interval; $U L C I=$ Upper level confidence interval. Bootstrap yeniden örnekleme $=5000$.

Tablo 3 incelendiğinde, proaktif kişilik ile kendini yetiştirme $(B=.297$, $\mathrm{t}=3.57, \mathrm{p}=.000$ ) pozitif yönlü ve anlamlı bir etkisi olduğu görülmüştür. Ayrıca tabloda, proaktif kişilik ile kariyer uyum yeteneği pozitif yönlü ve anlamlı bir etkisi olduğu görülmüştür $(\beta=.449, \mathrm{t}=10.44, \mathrm{p}=.000)$. Son olarak, aracı değişkenin (kendini yetiştirme) kariyer uyum yeteneğiyle pozitif yönlü ve anlamlı bir etkisi olduğu görülmüştür $(\beta=.013, \mathrm{t}=3.96, \mathrm{p}=.000)$. Bu kapsamda hipotezler kabul edilmiştir. Bu çalışmada, Hayes'in (2013) bootstrap yaklaşımına dayanan (5,000 örneklem) PROCESS bulguları, proaktif kişiliğin kendini yetiştirme vasıtasıyla kariyer uyum yeteneği üzerindeki dolaylı etkisinin anlamlı olduğu $(B=.047,95 \%$ BCA CI [.015, .087]) tespit edilmiştir. Modern yaklaşım ile yapılan analizde, dolaylı etkinin \% 95 bootstrap güven aralığ 1 (BCA CI $[.015, .087]$ ) değerleri 0 değerini kapsamadığından test edilen aracılık modelinin istatistiksel olarak anlamlı olduğu sonucuna ulaşılmıştır.

Buna göre, proaktif kişiliğin kariyer uyum yeteneği üzerinde dolaylı etkisinin anlamlı olduğu, dolayısıyla da kendinin yetiştirmenin proaktif kişilik ile kariyer uyum yeteneği arasındaki ilişkiye aracılık ettiği tespit edilmiştir. İki öğrenciden proaktif kişilik değeri diğer öğrenciden bir birim yüksek olan bir öğrencinin; proaktif kişiliği yüksek olan öğrencilerin kendini yetiştirmeye daha meyilli olması ve kendini yetiştiren öğrencilerin de kariyer uyum yeteneği düzeyinin daha yüksek olması nedeniyle kariyer uyum yeteneği düzeyi .039 birim daha yüksek olduğu şeklinde yorumlanabilir. 


\section{Tartışma ve Sonuç}

$\mathrm{Bu}$ çalışmada, proaktif kişiliğin kariyer uyum yeteneği üzerine etkisinde kendini yetiştirmenin rolü araştırılmıştır. Araştırmanın sonuçlarına göre, proaktif kişiliğin kariyer uyum yeteneğini pozitif yönde etkilediği belirlenmiştir. Bu sonuçlar, (Bateman ve Crant, 1993; Siebert vd. 1999; Crant, 2000; Tolentino vd., 2014; Hou vd., 2014; Cai vd., 2015; Li vd., 2015; Öncel, 2014) tarafından yapılan çalışmaların bulgularıyla örtüşmektedir. Yani proaktif kişiliğin kariyer uyum yeteneğini etkilediği bu çalışmayla da ortaya konulmuştur. Bununla birlikte, kendini yetiştirme, proaktif kişilik ile kariyer uyum yeteneği arasında aracılık rolü üstlenmektedir. Bu sonuçlar, (Abid vd., 2015; Jiang, 2017) tarafından yapılan çalışmaların bulgularıyla örtüşmektedir.

Çalışmada kurulan üç hipotezde desteklenmiştir. İlk 2 hipotez değişkenler arası ilişkilere odaklanmıştır. Bu kapsamda öğrencilerin proaktif kişilik özelliği artıkça öğrenme, canlılık, kendini yetiştirme ve kariyer uyum yetenekleri düzeyleri de artmaktadır. Bu değişkenler arasındaki ilişkiler pozitif yönlü ve orta kuvvet seviyesinde ve anlamlı bulunmuştur. Son hipotezi ile kendini yetiştirme, proaktif kişilik ile kariyer uyum yeteneği arasında aracılık rolü araştırılmıştır. Bu kapsamda hipotez kabul edilmiş olup, proaktif kişiliğin kariyer uyum yeteneğine üzerine etkisinde kendini yetiştirmenin aracılı̆̆ıyla olmaktadır.

Proaktif bireylerin iş bulmada ve kariyer uyumluluğu sağlamada daha avantajlı oldukları gözlenmiştir (Brow vd., 2006; Seibert vd., 1999; Tolentino vd., 2014). Bu sonuçlar ışığında, proaktif kişiliğin ilk olarak bireylerin okuldaki gelişimini desteklediğini ve bu sayede kariyer uyumunun geliştirilebileceğini göstermiştir. Bulgular, bireylerin daha proaktif olduklarında, okulda daha fazla kendilerini yetiştirme eğiliminde olduklarını ve daha sonra kariyer uyumunun gelişimini kolaylaştırdığını göstermektedir. Günümüz rekabet ortamında sürekli gerçekleşen değişime ayak uydurabilmek için değişime ve öğrenmeye açık, kendini yetiştirebilen öğrenciler önem arz etmektedir. Bununla birlikte, öğrencilerin kendilerini yetiştirmede yüksek düzeyde tutulabilmesi için akademisyenlerin veya da piyasada söz sahibi kişilerin fikirlerini ve önerilerini dikkate alarak kendilerini geliştirmeleri önerilmektedir. Proaktif kişilik özelliğine sahip öğrenci- 
lerin kariyer gelişimleri sürecinde kendini yetiştirebilmesi için akademisyenlere ve kariyer danışmanlarına görev düşmektedir. Üniversite dönemindeki öğrencilerin kişilik özellikleriyle çalışmayı hedefledikleri işler arasındaki uyumu sağlamaları kariyerleri açısından büyük önem taşımaktadir.

Araştırmanın çeşitli kısıtları bulunmaktadır. Sadece öğrenciler üzerinde yapılması, cevapların kullanılan ölçeklerle sınırlandırılması, boylamsal bir çalışma olmaması bu kısıtlar arasında sayılabilir. Ayrıca bilgi toplama aracı olarak ise öğrencilerin anket formundaki sorulara verdikleri cevapların gerçek durumu yansıttığ rın ortaya çıkmasında sosyal istenirlik etkisinin de varlığı söz konusu olabilir.

Gelecek çalışmalar için ise, bu çalışma işletme öğrencilerine yapıldığından dolayı diğer bölümlerle de yapılarak karşılaştırma yapılabilir. Ayrıca özel ve devlet üniversitelerinde farklı sonuçlar çıkabilir. Aynı zamanda farklı sektörlerde de uygulanabilir. Bu çalışma farklı değişkenler (kariyer inşası, beş faktör kişilik özellikleri, girişimcilik niyeti ve farklı kişilik özellikleri gibi) eklenerek farklı örneklemler üzerinde de çalışmalar önerilebilir. 


\title{
EXTENDED ABSTRACT
}

\section{The Role of Self Thriving in the Effect of Proactive Personality on Career Adaptability}

Seyhan Özdemir

\author{
Süleyman Demirel University
}

This study contributes to the field by investigating the mechanism underlying the relationship between proactive personality and career adaptability. It is suggested that the development of the psychological state in which individuals experience both vitality and a sense of learning serves as a means of transferring the effect of proactive personality to the formation process of the career adaptation process. Therefore, the role of self thriving was tried to be determined.

Career adaptability is a central concept that rests on the theory of career structuring. Career structuring theory explains how individuals construct their careers through personal and social constructivism (Savickas, 2005). Career adaptability can be defined as the coping skills of individuals in overcoming career development tasks, transitions such as changing jobs or schooling, or traumatic situations such as job loss (Savickas and Porfeli, 2012).

Individuals with proactive personality are less affected by the external environment and contribute more to environmental change. The tendency of people to act to influence their environment is to vary according to people. Proactive individuals are individuals who are aggressive, anticipate opportunities, take action, show initiative and strive with determination until they reach a meaningful change and goals, and differentiate from other employees (Bateman and Crant, 1993; Gupta and Bhawe, 2007). Proactive individuals have the ability to act more independently and make decisions in business and career stages (Siebert et al., 1999). Career adjustment reflects a process in which individuals build their professional lives dynamically and at the same time demonstrate their ability to proactively 
adapt to changes within the socio-cultural and socioeconomic conditions in which they live (Tladinyane ve Merwe, 2016).

As a result of the study, the role of self-thriving in the effect of proactive personality on career adaptation ability was investigated. According to the results of the study, it was determined that proactive personality had a positive effect on career adaptation ability. These results (Bateman and Crant, 1993; Siebert et al. 1999; Crant, 2000; Tolentino et al., 2014; Hou et al., 2014; Cai et al., 2015; Li et al., 2015; Öncel, 2014) support other studies. In other words, it has been demonstrated that proactive personality affects career adaptation ability. However, self-thriving acts as an intermediary between proactive personality and career adaptability. These results are consistent with the findings of the studies conducted by others (Abid et al., 2015; Jiang, 2017).

In this context, as the proactive personality traits of the students increase, their levels of learning, vitality, self-cultivation and career adaptation skills increase. The relationships between these variables were positively and moderately strong and significant. With the last hypothesis, the role of mediation between self-thriving, proactive personality and career adaptability was investigated. In this context, the hypothesis is accepted and the effect of proactive personality on career adaptability is through selfcultivation. Proactive individuals were found to be more advantageous in finding jobs and achieving career compliance (Brow et al., 2006; Seibert et al., 1999; Tolentino et al., 2014).

In light of these results, it has been shown that proactive personality first supports the development of individuals in the school and thus, career adaptation can be improved. The findings show that when individuals become more proactive, they tend to educate themselves more at school and then facilitate career development. In order to keep up with the changes that are taking place in today's competitive environment, students who are open to change and learning and able to train themselves are important. However, it is recommended that students develop themselves by taking into account the ideas and suggestions of academicians or people who have a say in the market. Academicians and career counselors have a duty to enable students with a proactive personality to develop themselves in their career development process. It is of great importance 
for the students in their careers to ensure the harmony between personality traits and the jobs they aim to work with. In addition by making KFA and DFA validity, it is suggested that the scales used in our study can be used in similar studies.

For future studies, since this study is conducted for business students, it can be compared with other departments. There may also be different results in private and public universities. It can also be conducted in different sectors. This study may be suggested by adding different variables (such as career building, five-factor personality traits, entrepreneurial intention, and different personality traits) on different sample

\section{Kaynakça / References}

Akın, A., Abacı, R., Kaya, M., ve Arıcı, N. (2011). Kısaltılmış proaktif kişilik ölçeği'nin (KPÖ) Türkçe formunun geçerlik ve güvenirliği. In ICES11 International Conference on Educational Sciences, June (pp. 22-25).

Bateman, T. S. ve Crant, J. M. (1993). The proactive component of organizational behavior: A measure and correlates. Journal of Organizational Behavior, 14(2), 103-118.

Brown, D. J., Cober, R. T., Kane, K., Levy, P. E., ve Shalhoop, J. (2006). Proactive personality and the successful job search: A field investigation with college graduates. Journal of Applied Psychology, 91(3), 717.

Cai, Z., Guan, Y., Li, H., Shi, W., Guo, K., Liu, Y., ... ,Hua, H. (2015). Selfesteem and proactive personality as predictors of future work self and career adaptability: An examination of mediating and moderating processes. Journal of Vocational Behavior, 86, 86-94.

Carmeli, A. ve Gittell, J. H. (2009). High-quality relationships, psychological safety, and learning from failures in work organizations. Journal of Organizational Behavior, 30(6), 709-729.

Duffy, R. D. (2010). Sense of control and career adaptability among undergraduate students. Journal of Career Assessment, 18(4), 420-430.

Fritz, M. S. veMacKinnon, D. P. (2007). Required sample size to detect the mediated effect. Psychological science, 18(3), 233-239. 
Gupta, V. K. ve Bhawe, N. M. (2007). The influence of proactive personality and stereotype threat on women's entrepreneurial intentions. Journal of Leadership \& Organizational Studies, 13(4), 73-85.

Gürbüz, S. ve Bayık, M. E. (2018). Aracılık modellerinin analizinde modern yaklaşım: Baron ve Kenny yöntemi artık terk edilmeli mi?. 6. Örgütsel Davranış Kongresi, Bildiriler Kitabı içinde (s.30-45) 2-3 Kasim 2018, Isparta.

Hartung, P. J. ve Taber, B. J. (2008). Career construction and subjective well-being. Journal of Career Assessment, 16(1), 75-85.

Hayes, A. F. (2018). Introduction to mediation, moderation, and conditional process analysis: A regression-based approach (2. Bask1). New York: The Guilford Press

Hayes, A. F. ve Matthes, J. (2009). Computational procedures for probing interactions in OLS and logistic regression: SPSS and SAS implementations. Behavior Research Methods, 41(3), 924-936.

Hou, C. , Wu, L. ve Liu, Z. (2014). Effect of proactive personality and decision-making self-efficacy on career adap-tability among chinese graduates. Social Behavior and Personality, 42(6), 903-912.

Jiang, Z. (2017). Proactive personality and career adaptability: The role of thriving at work. Journal of Vocational Behavior, 98, 85-97.

Jöreskog, K. G. ve Sörborm, D. (1993). Lisrel 8: Structual equation modeling with the simples command language. Lincolnwood: Scientific Software International, Inc.

Kanten, S. (2012). Kariyer uyum yetenekleri ölçeği: geçerlilik ve güvenilirlik çalişmasi. Journal of Süleyman Demirel University Institute of Social Sciences Year, 2(16), 191-205.

Kline, R. B. (2005). Principles and practice of structural equation modeling. New York: Guilford Press.

Koçak, Ö. F. (2017). How employees thrive at work? Importance of relatıonship quality, person-job fit and recovery experiences after work hours, Doctoral Thesis, Marmara Universities, Social Sciences Institute,Istanbul.

Lambert, T. A., Eby, L. T. ve Reeves, M. P. (2006). Predictors of networking intensity and network quality among white-collar job seekers. Journal of Career Development, 32(4), 351-365. 
Li, Y. , Guan, Y. , Wang, F. , Zhou, X. , Guo, K. , Jiang, P. , ... , Fang, Z. (2015). Big-five personality and bis/bas traits as predictors of career exploration: The mediation role of career adaptability. Journal of Vocational Behavior, 89, 39-45

MacKinnon, D. P., Lockwood, C. M., Hoffman, J. M., West, S. G. Ve Sheets, V. (2002). A comparison of methods to test mediation and other intervening variable effects. Psychological methods, 7(1), 83-104.

Morgan, G. A., Leech, N. L., Gloeckner, G. W. ve Barret, K. C. (2004). SPSS for introductory statistics: Use and interpretation, Second Edition. Lawrance Erlbaum Associates: London.

Öncel, L. (2014). Career adapt-abilities scale: Convergent validity of subscale scores. Journal of Vocational Behavior, 85, 13-17.

Parker, S. K., Bindl, U. K. ve Strauss, K. (2010). Making things happen: A model of proactive motivation. Journal of Management, 36(4), 827856.

Porath, C., Spreitzer, G., Gibson, C. ve Garnett, F. G. (2012). Thriving at work: Toward its measurement, construct validation, and theoretical refinement. Journal of Organizational Behavior, 33(2), 250-275.

Preacher, K. J. ve Hayes, A. F. (2004). SPSS and SAS procedures for estimating indirect effects in simple mediation models, Behavior research methods, instruments, \& computers, 36(4), 717-731.

Presbitero, A. (2015). Proactivity in career development of employees: the roles of proactive personality and cognitive complexity. Career Development International, 20(5), 525-538.

Ryan, R. M., ve Deci, E. L. (2000). Self-determination theory and the facilitation of intrinsic motivation, social development, and well-being. American Psychologist, 55(1), 68-78.

Savickas, M. L. (2005). The theory and practice of career construction. (R. W. Lent ve S. D. Brown Eds.), Career development and counseling: Putting theory and research to work, içinde (s. 42-70). Hoboken, NJ: John Wiley, USA.

Savickas, M. L. (2011). Constructing careers: Actor, agent, and author. Journal of Employment Counseling, 48(4), 179-181.

Savickas, M.L. ve Porfeli, E.J. (2012). The Career Adapt-Abilities Scale: Construction, reliability, and measurement equivalence across 13 countries, Journal of Vocational Behavior, 80, 661-673. 
Seibert, S. E., Crant, J. M., ve Kraimer, M. L. (1999). Proactive personality and career success. Journal of applied psychology, 84(3), 416-427.

Seibert, S. E., Kraimer, M. L., ve Liden, R. C. (2001). A social capital theory of career success. Academy of Management Journal, 44(2), 219-237.

Sevinç, A., ve Siyez, D. M. (2018). Öğrenci kariyer yapılandırma envanteri'nin Türkçe uyarlaması: Geçerlik ve güvenirlik çalışması. İş ve Insan Dergisi, 5(2), 157-168.

Skorikov, V. B. (2007). Adolescent career development and adjustment. Career Development in Childhood and Adolescence içinde (s. 237-254). Brill Sense.

Teichler, U. (1999). Internationalisation as a challenge for higher education in Europe. Tertiary Education \& Management, 5(1), 5-23.

Tladinyane, R. and Merwe, M. (2016). Career adaptability and employee engagement of adults employed in an insurance company: An exploratory study. Journal of Human Resource Management, 14 (1), 1-9.

Tuncer, D., Ayhan, D. Y. ve Varoğlu, D. B. (2011). Genel işletmecilik bilgileri. Siyasal Kitabevi.

Abid, G., Zahra, I. ve Ahmed, A. (2015). Mediated mechanism of thriving at work between perceived organization support, innovative work behavior and turnover intention. Pakistan Journal of Commerce and Social Sciences, 9(3), 982-998.

\section{Kaynakça Bilgisi / Citation Information}

Özdemir, S. (2019). Proaktif kişiliğin kariyer uyum yeteneğine etkisinde kendini yetiştirmenin rolü. OPUS-Uluslararası Toplum Araştırmaları Dergisi, 12(18. UİK Özel Sayıs1), 507-526. DOI: 10.26466/opus.583813. 